\section{Quirks and strong points}

Psychologists on Psychology. By David Cohen. Pp.360. (Routledge and Kegan Paul: London and Henley, 1977.) $£ 6.95$.

PSYCHOLOGY nowadays is a very mixed bag, and indeed some would query whether it is really just one bag. David Cohen's book, which is a series of interviews with successful psychologists, illustrates very well how far apart from one another they are. It is not so much that they disagree, though disagreements there are in plenty in this enterprising book. What is much more striking is that the different psychologists featured in this book are often so far apart in their subject matter, their approach, their conceptual frameworks, and their aims, that even mutual critcism is out of the question.

The interviews which David Cohen

\section{Androgen action}

The Mechanism of Action of Androgens. By W. I. P. Mainwaring. Pp. x+ 178. (Springer: New York and Berlin, 1977.) DM65.40; $\$ 28.80$.

THIS is a useful monograph written by an acknowledged expert in the field of androgen action. The book is an attempt to describe the molecular events associated with the entry of testosterone into androgen-sensitive cells and the subsequent metabolic changes associated with the presence of the hormone in these cells.

The author uses a temporal approach to the problem of the analysis of androgen action and, as usual, much of the material is drawn from experiments on the rat ventral prostate. The author is careful to point out the reservations which must be applied in generalising from this animal model to any other species or tissue.

The core of the book is devoted to an account of the initial events and the early and late events associated with androgen stimulation of target tissues. The author points out that, although androgens influence transcription and the synthesis of RNA, they may also affect other processes. The manner in which androgen metabolism in the target tissues influences the mode of action of androgens is considered in detail. The high affinity binding sites,

- In the review of Perpetual Motion: The History of an Obsession (Nature, 20 October, 269,731; 1977), the price should have read $£ 5.50$. gave to these stars of the behavioural world seem to have been well planned, and the questions are searching enough to bring out the subject's quirks as well as their strong points. Perhaps Cohen should have been more critical but even here there is an advantage of some interest, because the calmness of the interviews seems to have brought out into the open a staggering complacency in some of the psychologists concerned.

David Cohen's attempts at the beginning and end of the book to find some link between the backgrounds and personalities of the different interviewees - a psychology of psychologyare almost certainly ingenuous; these people are as diverse as their work. The interviews which form the core of this book, however, give a clear, conveniently quick though often disquieting picture of what many of the present leaders of psychology think they are up to.

P. E. Bryant

P. E. Bryant is Lecturer in Psychology at the University of Oxford, UK.

the intracellular transformation and the subsequent nuclear retention of the hormone are reviewed. The need to isolate and characterise the androgen receptor proteins is stressed. It is a pity that the author did not devote more attention to the effects of androgens on muscle and perhaps develop a working hypothesis or speculate on how they may affect this large body mass.

In the latter part of the book, the author critically reviews his own studies showing that some of the actions of androgens are explicable on the basis of the increased production of selected mRNAs and ribosomes. Thus, androgen action is at least in part an enhancement of genetic transcription.

The author writes: "The halcyon days of studies on the mechanism of action of androgen are drawing to a close." In fact, this excellent text is a clear indication that this is not so. Future research on the mode of action of androgens may, however, require more sophisticated approaches and more elegant tools. The book is clearly written and the reader gets the impression of being led through some of the mysteries of androgen action as in a series of lectures. The text has the stamp of authority. It is written by a scientist who has in fact uncovered many of the interesting facts on the mode of action of androgens. The book will be valuable to researchers and to university teachers concerned with the mode of action of steroid hormones in general and androgens in particular.

G. S. Boyd

G. S. Boyd is Professor of Biochemistry at the University of Edinburgh, UK.

\section{Geomorphology and remote sensing}

Remote Sensing in Geomorphology. By H. Th. Verstappen. Pp. $x+214$. (Elsevier Scientific: Amsterdam, New York and Oxford, 1977.) Dfl.98; \$39.95.

Thus well produced book will be valuable to the postgraduate or advanced research worker, rather than as an undergraduate textbook. A large amount of material is covered in a somewhat condensed style. Perhaps one of the chief merits of the book lies in its extensive bibliography of sources in English, German, Dutch, Russian and French languages. Of the 214 pages, approximately eleven are close printed lists of references, although some sources seem to have too brief a description, which may not be sufficient for procurement.

The pages are a source of constant stimulus: a technique or idea is introduced, and briefly described, but the reader will have to go to the original source for full details. This is perhaps a natural result of a text from an authority with the length and breadth of experience of the author.

The illustrations are plentiful and well produced. Some are in colour, and a notable feature is the number of stereopairs printed side by side for viewing with a pocket stereoscope.

Subjects covered include an historical introduction, a description of the types of imagery available, and available methods of interpretation. Chapters are devoted to image analysis based on relief (stereoscopy) and density criteria; pattern and texture are subsumed within these headings.

Geomorphology itself is divided into genetic and environment divisions, the latter including treatment of land systems methods of survey. This means that environments and major zones such as coastal, glacial, tropical and fluvial are discussed using examples hard upon one another's heels, with photography, radar, thermography and satellite imagery also intermingled. The examples used include lunar and planetary geomorphology. A final chapter deals briefly with such vital items as relative costs and fieldwork methods.

This is a most stimulating book, but one to be dipped into and used for reference or browsing. Because of the condensed staccato style, however, it is somewhat indigestible.

J. R. Hardy

J. R. Hardy is Senior Lecturer in Geography at the University of Reading, UK. 